Б. М. Урбагарова, В. В. Тараскин, Л. Д. Раднаева. Применение в медицине Saposhnikovia divaricata (Turcz.) Schischk.

Научная статья

УДК: 615.322

DOI: $10.18101 / 2306-1995-2021-1-31-39$

\title{
ПРИМЕНЕНИЕ В МЕДИЦИНЕ SAPOSHNIKOVIA DIVARICATA (TURCZ.) SCHISCHK.
}

Урбагарова Б. М., Тараскин В. В., Раднаева Л. Д.

\section{(C) Урбагарова Баярма Мунхоевна}

кандидат фармацевтических наук, старший преподаватель, Бурятский государственный университет имени Доржи Банзарова Россия, 670000, г. Улан-Удэ, ул. Смолина, 24а urbagarova.bayarma@mail.ru

\section{(C) Тараскин Василий Владимирович}

кандидат фармацевтических наук, старший научный сотрудник, Байкальский институт природопользования СО РАН

Россия, 670047, г. Улан-Удэ, ул. Сахьяновой, 6

старший преподаватель кафедры фармации, Бурятский государственный университет имени Доржи Банзарова Россия, 670000, г. Улан-Удэ, ул. Смолина, 24а vvtaraskin@mail.ru

\section{(C) Раднаева Лариса Доржиевна}

доктор химических наук, профессор, Бурятский государственный университет имени Доржи Банзарова Россия, 670000, г. Улан-Удэ, ул. Смолина, 24а

зав. лабораторией химии природных систем, Байкальский институт природопользования СО РАН Россия, 670047, г. Улан-Удэ, ул. Сахьяновой, 6 radld@mail.ru

Аннотация. Saposhnikovia divaricata (Turcz.) Schischk - перспективный азиатский эндемик. Данное растение произрастает в Китае, Корейской Республике, Японии и России. В статье собраны сведения о химическом составе корней, а также о фармакологическом действии как отдельных биологически активных веществ, так и суммарных веществ. Наличие высокой биологической активности и богатый химический состав обусловливают необходимость введения этого вида лекарственного растительного сырья - Saposhnikoviae divaricatae radices в Государственную фармакопею Российской Федерации и производство лекарственных средств на его основе. Учитывая перспективность широкого применения в медицинской практике, одновременно возникает вопрос решения проблемы сохранения биоразнообразия флоры России и разработки методов культивирования с учетом опыта зарубежных стран для обеспечения объемов промышленной заготовки сырья. В ходе обзора видно, что Saposhnikoviae divaricatae radices обладает противовоспалительной, обезболивающей, жаропонижающей, противоаллергической, антирадикальной, противогрибковой и антибактериальной активностью, что, безусловно, доказывает практическую ценность в медицине. 
Ключевые слова: Saposhnikovia divaricata (Turcz.) Schischk.; Apiaceae; эфирные масла; $\beta$-бисаболен; (Z)-фалькаринол; Fang Feng; лекарственное растительное средство; лекарственное растительное сырье

Благодарности. Данная статья выполнена в рамках проекта БГУ «Исследование биологически активных соединений с антирадикальной активностью узкоареальных и эндемичных видов растений».

\section{Для цитирования}

Урбагарова Б. М., Тараскин В. В., Раднаева Л. Д. Применение в медицине Saposhnikovia divaricata (Turcz.) Schischk. // Вестник Бурятского государственного университета. Медицина и фармация. 2021. № 1. С. 31-39.

Сапожниковия растопыренная (Saposhnikovia divaricata (Turcz.) Schischk.) единственный вид рода Saposhnikovia Schischk., относится к семейству Зонтичные (Umbelliferae), или Сельдерейные (Apiaceae). Сапожниковия растопыренная является важным компонентом клинической практики в Китае, Корее и Японии в качестве эффективного противовоспалительного средства для лечения артралгии, ревматизма, генерализованных и головных болей, при инсультах, лихорадке, простудных заболеваниях и аллергических ринитах, а также как анальгезирующее, противпаркинсоническое в составе многокомпонентных сборов [1]. Saposhnikoviae divaricatae radices является официнальным лекарственным средством растительного происхождения Китая (Fang Feng), Республики Корея (Bangpung) и Японии (Bofu) [1-3]. Известно, что в народной медицине Монголии используются плоды сапожниковии растопыренной как общеукрепляющее средство. Также известно применение сока из травы данного растения, обладающего антимикробной активностью против Pseudomonas aeruginosa и Staphylococcus aureus. Известен ряд лекарственных средств, содержащих сапожниковии растопыренной корни: Shen Nung Pen Tsao Ching - анальгезирующее средство, Chuanxiong Chatiao противопаркинсонический многокомпонентный сбор, Tong-Xie-Yao-Fang - cбор, применяющийся при синдроме раздраженного кишечника и другие [4-9].

На сегодняшний день Saposhnikovia divaricata (Turcz.) Schischk. активно исследуется учеными разных стран, что подтверждается ростом публикационной активности. Таким образом, целью настоящей статьи является проведение систематического обзора исследований Saposhnikovia divaricata (Turcz.) Schischk.

Родовое название дано ботаником Б. К. Шишкиным в честь известного российского ботаника и путешественника В. В. Сапожникова [10], но также известны другие названия: «Fang Feng», «Bofu», «Bangpung», имеющие одинаковое значение - «защита от ветра». Помимо «языковых» названий сапожниковия растопыренная имеет ботанические синонимы: Ledebouriella divaricata (Turcz.) M. Hiroe, Siler divaricatum (Turcz.) Benth. et Hook. f., Stenocoelium divaricatum Turcz., Laser divaricatum (Turcz.) Thell., Saposhnikovia seseloides Kitag. Столь большое количество синонимичных названий можно объяснить тем, что до того, как был выделен род Saposhnikovia Schischk., данный вид относили к родам Stenocoelium (Turczaninow, 1844; Ledebour, 1844), Siler (Bentham, 1867), Laser (Thellung, 1925) или Ledebouriella (Hiroe, 1958, 1979). На сегодня установлено, что Saposhnikovia divaricata (Turcz.) Schischk. является единственным видом в роду 
Б. М. Урбагарова, В. В. Тараскин, Л. Д. Раднаева. Применение в медицине Saposhnikovia divaricata (Turcz.) Schischk.

Saposhnikovia Schischk. семейства Apiaceae Lindl. Самостоятельность рода Saposhnikovia выявлена в ходе сравнительного анализа таксономических связей с родом Ledebouriella. Например, при изучении нуклеотидных последовательностей разных участков генома Saposhnikovia divaricata показано, что Saposhnikovia близка к Peucedanum japonicum (горичник японский), Seseli tortuosum и некоторым другим видам Seseli, а также к Phlojodicarpus и Kitagawia (рис. 1) [11].

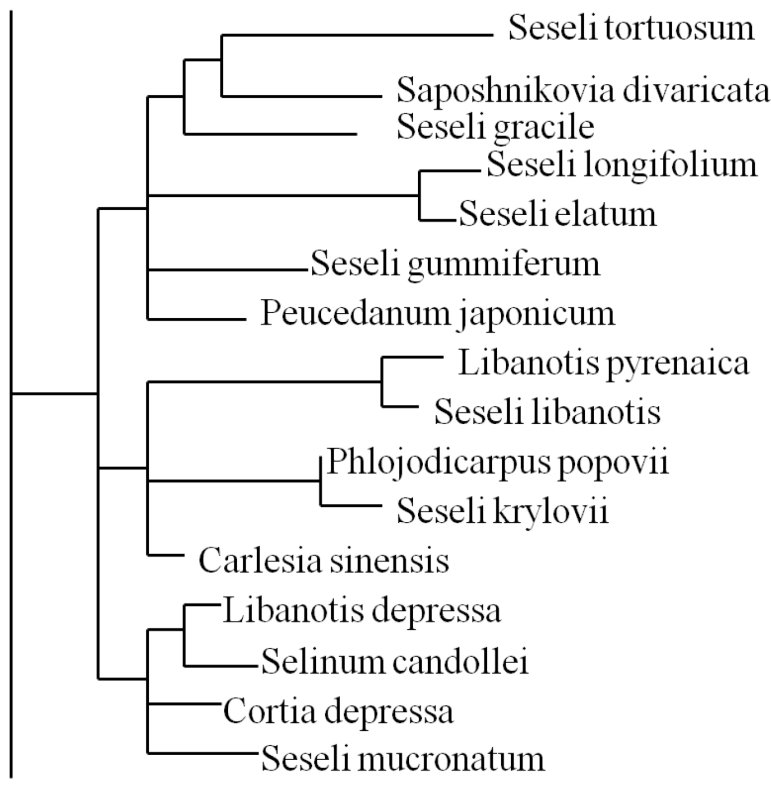

Seseli

Рис. 1. Филогенетическое положение Saposhnikovia divaricata (Turcz.) Schischk. [11]

Ареал произрастания охватывает территории Монголии, северной и северовосточной территории Китая, Корейского полуострова и Российской Федерации [12-13]. В России сапожниковия растопыренная произрастает в южной области Восточной Сибири и юго-западной части Дальнего Востока, в таких регионах, как Республика Бурятия, Амурская область, Забайкальский, Хабаровский и Приморский края. На территории Республики Бурятия вид встречается в Иволгинском, Тарбагатайском, Бичурском, Мухоршибирском, Джидинском, Кяхтинском районах.

Ввиду высокой ценности данного растения для медицины сапожниковия растопыренная культивируется в Китае в провинциях Аньхой, Шаньси и Ганьсу [14]. С 2005 г. на территории Германии проводятся работы по культивированию лекарственных растений, в том числе Saposhnikovia divaricata, с целью получения высококачественных растений, соответствующих требованиям надлежащей сельскохозяйственной практики (GAP) [15]. По данным литературы известно, что всхожесть семян сапожниковии растопыренной напрямую зависит от температурного режима и при температуре $20-22{ }^{\circ} \mathrm{C}$ составляет 55 дней, в то время как в более теплой среде $\left(28-30^{\circ} \mathrm{C}\right)$ всего лишь 28 дней [16]. Ввиду этого сотрудниками Хэйлунцзянского университета китайской медицины (г. Харбин, 
Китай) исследовано влияние температурного фактора на фармакокинетические параметры in vivo, так, выявлено, что при воздействии тепла $\left(\mathrm{t}^{\mathrm{0}}=30^{\circ} \mathrm{C}\right)$ в течение 6 дней концентрация цимифугина увеличивается на $50.6 \%$, что ведет соответственно к усилению жаропонижающего, обезболивающего и противовоспалительного эффектов [17]. В Республике Бурятия с 2018 г. также ведутся работы по интродукции сапожниковии растопыренной доктором фармацевтических наук, профессором, заслуженным деятелем науки Республики Бурятия Т. А. Асеевой [18].

Помимо культивирования растения в почве, проведена работа по соматическому эмбриогенезу in vitro, в результате чего выявлено, что в течение 15 месяцев можно получить уже цветущие и плодоносящие объекты, в то время как природные и культивированные растения цветут только через 2-3 года [19]. Данные исследования имеют важное значение для фармацевтической области и в решении экологических проблем в плане восстановления урона окружающей среде в процессе заготовки сырья.

Химический состав сапожниковии растопыренной корней представлен соединениями различной природы - хромоны, кумарины, полиацетиленовые и азотсодержащие соединения, фенолкарбоновые кислоты, стероиды, жирные кислоты и полисахариды. Основными действующими веществами сапожниковии растопыренной корней считаются хромоны (перв-О-глюкозилцимифугин и 4 '-О- $\beta$-D-глюкозил-5-О-метилвиссаминол), в связи с этим в соответствии с требованиями фармакопеи КНР стандартизацию ведут по содержанию именно этих веществ (суммарное количество не менее 0.24\%) [20]. В настоящее время в традиционной китайской медицине корни данного растения используются в виде отвара в качестве жаропонижающего средства, а этанольный экстракт обладает противовоспалительным и противопростудным действиями [1, с. 20]. Этанольный экстракт сапожниковии растопыренной корней обладает антиоксидантной активностью in vitro, значительно снижая продукцию NO клетками RAW, активированными LPS [21]. В научном исследовании M. Kim и др. в 2018 г. подтверждена выраженная антиоксидантная и противомикробная (в отношении грамотрицательных и грамположительных бактерий) активность эфирной и этилацетатной вытяжки метанольного экстракта корней Saposhikovia divaricata, что можно объяснить высоким содержанием полифенольных соединений [22]. Группой японских ученых исследовано анальгезирующее действие фракций этилацетатной вытяжки [23]. В недавнем исследовании китайскими учеными проведен сравнительный анализ в проявлении тремя доминирующими хромонами (цимифугин, перв-О-глюкозилцимифугин и 4'-О- $\beta$-D-глюкозил-5-О-метилвисамминол) жаропонижающей, анальгезирующей и противовоспалительной активностей, выявлено, что цимифугин обладает более выраженным, быстрым и продолжительным жаропонижающим эффектом в отличие от перв-О-глюкозилцимифугина. При исследовании анальгезирующей активности цимифугин также проявил более выраженный обезболивающий эффект в отличие от перв-Оглюкозилцимифугина и 4'-O- $\beta$-D-глюкозил-5-О-метилвисамминола. Эти же вещества оказывают выраженный противовоспалительный эффект [24]. S. Khan и др. в 2013 г. изучили механизм противовоспалительного действия Saposhnikoviae divaricatae radices. Так, данный эффект развивается вследствие ингибирования ядерного фактора NF-kB и митоген-активируемых протеинкиназ (MAPK) [25]. 
Б. М. Урбагарова, В. В. Тараскин, Л. Д. Раднаева. Применение в медицине Saposhnikovia divaricata (Turcz.) Schischk.

В 2015 г. опубликована научная работа по выявлению механизмов противовоспалительного действия 4'-O- $\beta$-D-глюкозил-5-О-метилвиссаминола в модели субарахноидального кровоизлияния на крысах. Доказано, что 4'-O- $\beta$-D-глюкозил-5О-метилвиссаминол ослабляет экспрессию медиаторов иммунитета: интерлейкина- $1 \beta$, интерлейкина- 6 и моноцитарного хемоаттрактантного белка-1, также известного как хемокиновый лиганд 2. Моноцитарный хемоаттрактантный белок-1 является одним из основных хемокинов, который регулирует миграцию и инфильтрацию моноцитов и макрофагов при субарахноидальном кровоизлиянии на начальной стадии. Также известно, что хемокиновый лиганд 2 индуцируется и участвует в различных заболеваниях, таких как идиопатическая воспалительная миопатия, цитомегаловирусный энцефалит, атеросклероз, болезнь Альцгеймера, черепно-мозговая травма и ревматическая артропатия. Кроме этого, данный лиганд индуцирует экспрессию амилина, а при повышении активности амилина в плазме развивается резистентность к инсулину при ожирении. Показано, что 4'O- $\beta$-D-глюкозил-5-О-метилвиссаминол блокирует каспазу-9а (инициатора апоптоза) и снижает эффекторную каспазу-3 (основной эффектор нейронального апоптоза). Таким образом, данный хромон снижает нейровоспаление и ослабляет апоптоз клеток головного мозга на ранней стадии субарахноидального кровоизлияния [26].

Пиранохромон втор-О-глюкозилгамаудол в исследованиях S. H. Kim и др. [27] показал анальгетическую активность при интратекальном введении мышам на модели формалин-вызванной боли. Данное соединение дозозависимо уменьшило тремор мышц, что указывает на проявление антиноцицептивной активности, связанной с влиянием на опиоидные рецепторы.

В области фармакокинетических исследований выявлено, что перв-Оглюкозилцимифугин является пролекарством цимифугина, а 4'-O- $\beta$-D-глюкозил5-О-метилвисамминол не обнаруживается в крови после перорального применения [28]. Как говорилось выше, сапожниковия растопыренная применяется в качестве противоаллергического средства. Так, Xiaoyu Wang и др. изучен механизм антигистаминного действия фуранохромона - цимифугина. Цимифугин в модели аллергического дерматита снижал образование тимуса стромального лимфопоэтина TSLP (цитокин, подобный IL-7, который сильно индуцирует дерегулирование Th2-лимфоцитов) и интерлейкина IL-33 (цитокин семейства цитокинов IL-1, является ключевым инициатором иммунитета 2-го типа, обнаруженным при аллергическом воспалении) путем регулирования плотных соединений ТJ эпителиальных клеток. Учитывая полученные результаты, авторы работы рекомендуют использовать цимифугин в качестве терапевтического и профилактического средства при аллергических заболеваниях, в том числе при атопическом дерматите [29].

Особое внимание уделяется исследованиям противоопухолевых свойств. Известно, что экстракт сапожниковии растопыренной корней оказывает аддитивное влияние на химиотерапевтические препараты (камптотецин и паклитаксел) в опухолевых клетках хронической миелогенной лейкемии (K562), промиелоцитарной лейкемии (HL60) и в клетках аденокарциномы протоков молочной железы человека (MCF7), опухоли молочной железы (MDA-MB-468), соответственно. Это наблюдение имеет потенциальное клиническое значение, так как предпола- 
гает снижение доз химиотерапевтических препаратов ввиду их токсичности без снижения антипролиферативного эффекта [30]. Результаты нашей работы также подтверждают эти исследования, так в работе [31-32] выявлена избирательная цитотоксичность в отношении раковых клеток молочной железы ВT-474 и MDAMB-231 цимифугина, следует отметить, что гликозиды глюкозилгамаудол и 4'-О$\beta$-D-глюкозил-5-О-метилвисамминол обладали большей цитотоксичностью по сравнению с хромонами гамаудол и 5-О-метилвисамминол.

Анализ имеющихся научных данных позволяет говорить о наличии широкого спектра активностей экстрактов и индивидуальных метаболитов сапожниковии растопыренной корней (противовоспалительной, анальгезирующей, жаропонижающей, противоаллергической, антиоксидантной, противогрибковой, антибактериальной) и вместе с тем открывает перспективы для дальнейшего детального изучения данного вида с фармацевтической, фармакологической и ботанической точек зрения.

Литература

1. Saposhnikoviae divaricata: a phytochemical, pharmacological, and pharmacokinetic review / J. Kreiner, E. Pang, G. B. Lenon, A. W. H. Yang // Chinese Journal of Natural Medicines. 2017. V. 15(4). P. 255-264.

2. The Japanese Pharmacopoeia / The Ministry of Health, Labour and Welfare. 2016.

3. The Korean Pharmacopoeia / South Korea's Ministry of Food and Drug Safety. 2018.

4. Quality assurance for Chinese herbal formulae: standardization of IBS-20, a 20-herb preparation / S.-P. Ip, M. Zhao, Y. Xian [et al.] // Chinese Medicine. 2010. V. 5. P. 8.

5. Recent advances in herbal medicines treating Parkinson's disease / X-zh. Li, Sh-n. Zhang, S-m Liu, F. Lu // Fitoterapia. 2013. V. 84. P. 273-285.

6. Metabolic profiling of the traditional Chinese medicine formulationYu Ping Feng San for the identification of constituents relevant foreffects on expression of TNF- $\alpha$, IFN- $\gamma$, IL-1 $\beta$ and IL-4 in U937 cells / N. Stefanie, M. Marlene, Z. Huiqin [et al.] // Journal of Pharmaceutical and Biomedical Analysis. 2017. V. 145. P. 219-229.

7. The effect of Da-Fang-Feng-Tang on treatment of type II collagen-induced arthritis in DBA/1 mice / L. R. Wang, N. Ishiguro, E. Yamada [et al.] // American Journal of Chinese Medicine. 1991. V. 27 (2). P. 205-215.

8. HPLC-MS and HPLC-MS/MS analysis of seven active constituents of Xiao-Xu-Ming decoction and application to a pharmacokinetic study after oral administration to rat / Y. Wang, Ch. Ding, C. Wu [et al.] // Acta Pharmaceutica Sinica B. 2012. V. 2(2). P. 188-197.

9. Qualitative and quantitative analysis of chemical constituents in traditional Chinese medicinal formula Tong-Xie-Yao-Fang by high-performance liquid chromatography/diode array detection/electrospray ionization tandem mass spectrometry / Zh. Yan, X. Yang, J. Wu [et al.] // Analytica Chimica Acta. 2011. V. 691. P. 110-118.

10. Куприянов А. Н. Арабески ботаники. Книга вторая: Томские корни. Кемерово: Вертоград, 2008. 224 с. Текст: непосредственный.

11. Spalik K., Reduron J.-P., Downie S. R. The phylogenetic position of Peucedanum sensu lato and allied genera and their placement in tribe Selineae (Apiaceae, subfamily Apioideae) // Plant Systematics and Evolution. 2004. V. 243. P. 189-210.

12. Аненхонов О. А. Определитель растений Бурятии. Улан-Удэ: Изд-во БНЦ СО РАН, 2001. 670 с. Текст: непосредственный.

13. Растительные ресурсы России. Дикорастущие цветковые растения, их компонентный состав и биологическая активность. Т. 3. Семейства Fabaceae-Apiaceae / ответственный редактор А. Л. Буданцев. Санкт-Петербург; Москва: Товарищество научных изданий КМК, 2010. 601 с. Текст: непосредственный. 
Б. М. Урбагарова, В. В. Тараскин, Л. Д. Раднаева. Применение в медицине Saposhnikovia divaricata (Turcz.) Schischk.

14. Mineral Elements in Root of Wild Saposhnikovia divaricate and Its Rhizosphere Soil / J.-B. Sun, Y.-G. Gao, P. Zang [et al.] // Biological Trace Element Research. 2013. V. 153. P. 363-370.

15. Cultivation and Breeding of Chinese Medicinal Plants in Germany / H. Heuberger, R. Bauer, F. Friedl [et al.] // PlantaMed. 2010. V. 76. P. 1956-1962.

16. Physical and Ecological Impacts of Chromones of Fresh Root of Saposhnikovia divaricata Exposure to High Temperature / H. Jian, J. M. Yang, G. Z. Jia [et al.] // Russian Journal of Plant Physiology. 2018. V. 65(5). P. 680-687.

17. Exposure to high temperature condition enhances the antipyretic, analgesic and antiinflammatory of Saposhnikovia divaricata fresh root / H. Jiang, J.-M. Yang, L. Cao, X.-C. Meng // Амурский медицинский журнал. 2017. № 3. С. 40-41.

18. Развитие лекарственного растениеводства на Байкальской природной территории / составители В. М. Шишмарев, Т. М. Шишмарева, Т. А. Асеева. Улан-Удэ: Изд-во БНЦ СО РАН, 2018. 152 с. Текст: непосредственный.

19. Somatic Embryogenesis and in vitro Flowering in Saposhnikovia divaricata / Q. Qiao, F.-W. Xing, Y.-P. Xiao, H.-F. Chen // Journal of Plant Growth Regulation. 2009. V. 28. P. 81-86.

20. The Chinese Pharmacopoeia / Chinese Pharmacopoeia Commission. 2015.

21. Tai J., Cheung S. Anti-proliferative and antioxidant activities of Saposhnikovia divaricata // Oncology Reports. 2007. V. 18. P. 227-234.

22. Kim M., Seo K.-S., Yun K.W. Antimicrobial and Antioxidant Activity of Saposhnikovia divaricata, Peucedanum japonicum and Glehnia littoralis // Indian Journal of Pharmaceutical Sciences. 2018. V. 80 (3). P. 560-565.

23. Analgesic Components Of Saposhnikovia Root (Saposhnikovia divaricata) / E. Okuyama, T. Hasegawa, T. Matsushita [et al.] // Chemical And Pharmaceutical Bulletin. 2001. V. 49(2). P. 154-160.

24. Feeble Antipyretic, Analgesic, and Anti-inflammatory Activities were Found with Regular Dose 4'-O- $\beta$-D-Glucosyl-5-OMethylvisamminol, One of the Conventional Marker Compounds for Quality Evaluation of Radix Saposhnikoviae / J.-M. Yang, H. Jiang, H.-L. Dai [et al.] // Pharmacognosy Magazine. 2017. P. 168-174.

25. Khan S., Kim Y. Sh. Molecular Mechanism of Inflammatory Signaling and Predominant Role of Saposhnikovia divaricata as Anti-inflammatory Potential // Natural Product Sciences. 2013. V. 19(2). C.120-126.

26. 4'-O- $\beta$-d-glucosyl-5-O-methylvisamminol, an active ingredient of Saposhnikovia divaricata, attenuates high-mobility group box 1 and subarachnoid hemorrhage-induced vasospasm in a rat model / Ch. - Z. Chang, Sh. ${ }^{-}$Ch. Wu, A. - L. Kwan, Ch. ${ }^{-}$L. Lin // Behavioral and Brain Functions. 2015. V. 11(1). P. 1-13.

27. Antinociceptive effect of intrathecal sec-O-glucosylhamaudol on the formalin-induced pain in rats / S. H. Kim, H. S. Jong, M. H. Yoon [et al.] // The Korean Journal of Pain. 2017. V. 30(2). P. 98-103.

28. Feeble Antipyretic, Analgesic, and Anti-inflammatory Activities were Found with Regular Dose 4'-O- $\beta$-D-Glucosyl-5-OMethylvisamminol, One of the Conventional Marker Compounds for Quality Evaluation of Radix Saposhnikoviae / J.-M. Yang, H. Jiang, H.-L. Dai [et al.] // Pharmacognosy Magazine. 2017. P. 168-174.

29. Cimifugin suppresses allergic inflammation by reducing epithelial derived initiative key factors via regulating tight junctions / X. Wang, X. Jiang, X. Yu [et al.] // Journal of Cellular and Molecular Medicine. 2017. V. 20(10). P. 1-11.

30. Tai J., Cheung S. Anti-proliferative and antioxidant activities of Saposhnikovia divaricata // Oncology Reports. 2007. V. 18. P. 227-234. 
31. Chromones and coumarins from Saposhnikovia divaricata (Turcz.) Schischk. Growing in Buryatia and Mongolia and their cytotoxicity / B. M. Urbagarova, E. E. Shults, V. V. Taraskin [et al.] // Journal of Ethnopharmacology. 2020. URL: https://doi.org/10.1016/j.jep.2019.112517.

32. Урбагарова Б. М. Фармакогностическое исследование сапожниковии растопыренной (Saposhnikovia divaricata (Turcz.) Schischkin) корней и разработка на их основе экстракта сухого: диссертация на соискание ученой степени кандидата фармакологических наук. Улан-Удэ, 2019. 162 с. Текст: непосредственный.

Статья поступила в редакиию 09.01.2021; одобрена после рецензирования 25.01.2021; принята к публикациии 09.04.2021.

\section{MEDICINAL USE OF SAPOSHNIKOVIA DIVARICATA (TURCZ.) SCHISCHK.}

Urbagarova B. M. ${ }^{1}$, Taraskin V. V., ${ }^{1,2}$, Radnaeva L. D. ${ }^{1,2}$

Bayarma M. Urbagarova

Cand. Sci. (Pharmacy), Senior Lecturer of Pharmacy Department

Dorzhi Banzarov Buryat State University

24a Smolina St., Ulan-Ude 670000, Russia

urbagarova.bayarma@mail.ru

Vasiliy V. Taraskin

Cand. Sci. (Pharmacy), Senior Researcher,

Laboratory of Natural Systems Chemistry,

Baikal Institute of Environmental Management SB RAS

6 Sakhyanovoy St., Ulan-Ude 670047, Russia

Senior Lecturer of Pharmacy Department

Dorzhi Banzarov Buryat State University

24a Smolina St., Ulan-Ude 670000, Russia

vvtaraskin@mail.ru

Larisa D. Radnaeva

Dr. Sci. (Chemistry), Prof.,

Dorzhi Banzarov Buryat State University

24a Smolina St., Ulan-Ude 670000, Russia

Head of Laboratory of Natural Systems Chemistry,

Baikal Institute of Nature Management SB RAS

6 Sakhyanovoy St., Ulan-Ude 670047, Russia

radld@mail.ru

Abstract. Saposhnikovia divaricata (Turcz.) Schischk. is an Asian endemic medicinal plant. It grows in China, the Republic of Korea, Japan and Russia. This article presents information on the chemical composition, pharmacological effect, and cultivation of Saposhnikovia divaricata (Turcz.) Schischk. High biological activity and rich chemical composition of this medicinal plant necessitate its introduction into the State Pharmacopoeia of the Russian Federation and production of medicines based on it. The prospects of widespread using Saposhnikovia divaricata radices in medical practice raise the problems of preserving the biodiversity of the Russian flora and developing methods of cultivation taking into account 
Б. М. Урбагарова, В. В. Тараскин, Л. Д. Раднаева. Применение в медицине Saposhnikovia divaricata (Turcz.) Schischk.

the experience of foreign countries to ensure the volume of industrial procurement of raw materials. The review have shown that Saposhnikoviae divaricatae radices have antiinflammatory, analgesic, antipyretic, anti-allergic, anti-radical, antifungal and antibacterial activities, which certainly proves its practical value in medicine.

Keywords: Saposhnikovia divaricata (Turcz.) Schischk., Apiaceae, essential oils, $\beta$-bisabolic, (Z)-falcarinol, Fang Feng, herbal medicine, herbal substances

Acknowledgments. The article was carried out within the framework of Buryat State University project "Investigation of Biologically Active Compounds with Antiradical Activity in Narrow-Range and Endemic Plant Species".

For citation

Urbagarova B. M., Taraskin V. V., Radnaeva L. D. Medicinal Use of Saposhnikovia Divaricata (Turcz.) Schischk. Bulletin of Buryat State University. Medicine and Pharmacy. 2021; 1: 31-39 (In Russ.)

The article was submitted 09.01.2021; approved after reviewing 25.01.2021; accepted for publication 09.04.2021. 